\title{
Skin Wound Healing: An Update on the Current Knowledge and Concepts
}

\author{
Heiko Sorga ${ }^{a}$ Daniel J. Tilkorn ${ }^{a}$ Stephan Hager ${ }^{a}$ Jörg Hauser ${ }^{a}$ \\ Ursula Mirastschijski ${ }^{\text {b, c }}$ \\ a Department of Plastic, Reconstructive and Aesthetic Surgery, Hand Surgery, Alfried Krupp \\ Krankenhaus Essen, Essen, ${ }^{b}$ Department of Plastic, Reconstructive and Aesthetic Surgery, \\ Klinikum Bremen-Mitte, and ${ }^{\mathrm{C} C B I B}$, University of Bremen, Bremen, Germany
}

\section{Keywords}

Inflammation · Proliferation · Angiogenesis · Nonthermal plasma · Scarring

\begin{abstract}
Background: The integrity of healthy skin plays a crucial role in maintaining physiological homeostasis of the human body. The skin is the largest organ system of the body. As such, it plays pivotal roles in the protection against mechanical forces and infections, fluid imbalance, and thermal dysregulation. At the same time, it allows for flexibility to enable joint function in some areas of the body and more rigid fixation to hinder shifting of the palm or foot sole. Many instances lead to inadequate wound healing which necessitates medical intervention. Chronic conditions such as diabetes mellitus or peripheral vascular disease can lead to impaired wound healing. Acute trauma such as degloving or large-scale thermal injuries are followed by a loss of skin organ function rendering the organism vulnerable to infections, thermal dysregulation, and fluid loss. Methods: For this update article, we have reviewed the actual literature on skin wound healing purposes focusing on the main phases of wound healing, i.e., inflammation, proliferation, epithelialization, angiogenesis, remodeling, and scarring. Results: The reader will get briefed on new insights and up-to-date concepts in skin wound healing. The macrophage as a key player in the inflammatory phase will be highlighted. During the epithelialization process, we will present the different concepts of how the wound will get closed, e.g., leapfrogging, lamellipodial crawling, shuffling, and the stem cell niche. The neovascularization represents an essential component in wound healing due to its fundamental impact from the very beginning after skin injury until the end of the wound remodeling. Here, the distinct pattern of the neovascularization process and the special new functions of the pericyte will be underscored. At the end, this update will present 3 topics of high interest in skin wound healing issues, dealing with scarring, tissue engineering, and plasma application. Conclusion: Although wound healing mechanisms and specific cell functions in wound
\end{abstract}


repair have been delineated in part, many underlying pathophysiological processes are still unknown. The purpose of the following update on skin wound healing is to focus on the different phases and to brief the reader on the current knowledge and new insights. Skin wound healing is a complex process, which is dependent on many cell types and mediators interacting in a highly sophisticated temporal sequence. Although some interactions during the healing process are crucial, redundancy is high and other cells or mediators can adopt functions or signaling without major complications.

(C) 2016 S. Karger AG, Base

\section{Introduction}

Skin wound healing is a fascinating mechanism and represents an evolutionary advantage not only for mammals. Due to its vital functions as a physical, chemical and bacterial barrier, skin wound healing is an important step for survival finalizing in wound closure. Despite a great body of literature with regard to wound healing mechanisms, there are still many questions. Physiological regulation of skin wound healing is a complex process, which is dependent on many cell types and mediators interacting in a highly sophisticated temporal sequence. Although some interactions during the healing process are crucial, redundancy is high and other cells or mediators can adopt functions or signaling without major complications. The purpose of the following update on skin wound healing is to focus on the different phases briefing the reader on actual knowledge and new insights. At the end, this update will briefly focus on 3 topics of high interest, i.e., scarring, tissue engineering in skin wound repair, and plasma application in skin wound healing.

\section{From Inflammation to Proliferation}

One of the main reasons for skin wound healing seems to be the restoration of the barrier function in order to prevent further damage or infection. This requires the distinct interplay and crosstalk of a multitude of cells and mediators from the very onset. However, prolonged wound healing phases or excessive responses of the organism to the injury impede normal wound healing and might be associated with scarring. In this context, the transition from the inflammatory to the proliferative stage of wound repair is a topic of intensive current research [1]. First of all, skin cells are exposed to acute phase signals such as damage-associated molecular patterns or pathogen-specific molecular patterns, which are recognized on their parts by toll-like receptors initiating and perpetuating inflammation [2, 3]. Leukocytes, especially neutrophil granulocytes, transmigrate alongside an increasing gradient of chemokines until arrival at the site of injury [4, 5]. In addition, neutrophils secrete many pro-inflammatory cytokines and thereby amplify the inflammatory response [6]. The influence of cytokines and chemokines in wound repair has been extensively reviewed elsewhere [7, 8]. Activated regulatory $T$ cells are part of the adaptive immune system. Aside from leukocytes, regulatory $\mathrm{T}$ cells are able to regulate tissue inflammation via the attenuation of the interferon- $\gamma$ production and the accumulation of pro-inflammatory macrophages. It is assumed that this effect is mediated by the epidermal growth factor receptor pathway, which is coopted for the facilitation of skin wound repair [9].

One of the key players in the transition from inflammation to proliferation is, however, the macrophage $[1,10]$. Depletion studies showed that the absence of macrophages in the inflammatory or the proliferation phase of wound healing resulted in reduced tissue formation or hemorrhage. Furthermore, the progression into the next scheduled phase failed [11]. Skin- 
resident macrophages as well as those differentiated from infiltrating monocytes get activated by pathogen-specific molecular patterns and damage-associated molecular patterns [2]. In early stages of wound repair, this results in the differentiation into the M1 subset of macrophages. M1 macrophages are associated with phagocytic activity, scavenging as well as the production of pro-inflammatory mediators [10,12,13]. Later on, M1 transform into the M2 subset, revealing a reparative phenotype of macrophages. M2 macrophages are involved in the synthesis of anti-inflammatory mediators and the production of extracellular matrix (ECM), in the initiation of fibroblast proliferation as well as in angiogenic processes $[10,14]$. M2 macrophages constitute a kind of cleanup crew as they phagocytose neutrophils (i.e., efferocytosis), bacteria, and cell debris in order to prevent further damage to the wound site in later healing phases. This supports the current paradigm of the M1-M2 switch $[1,15]$. If the M1-M2 transition does not occur, nonhealing or chronic wounds such as venous ulcers and diabetic wounds are the result [16-18]. These observations underpin the intimate and important role of macrophages throughout the process of skin wound healing. In contrast to the above-mentioned, however, many cellular or cytokine actions might get adopted by other cells as Martin et al. [19] could demonstrate that even macrophage-deficient PU.1 null mice were able to repair skin wounds with a similar time course to wild-type mice. Furthermore, these PU.1 null mice showed almost scar-free healing, questioning the impact of the inflammatory response for the skin wound healing process [19].

\section{Epithelialization in Skin Wound Healing}

Cutaneous wounds close by epithelial resurfacing and wound contraction. Dependent on the species, one or the other process dominates the progress of wound repair. For example, rodents heal mainly by contraction, whereas in humans, reepithelialization accounts for up to $80 \%$ of wound closure [20]. Skin wound epithelialization is reliant on the wound specifics such as the location, the depth, the size, microbial contamination as well as patient-related health conditions, genetics and epigenetics.

Partial thickness wounds that involve the epidermis and partially the dermis usually heal by primary intention with intact skin appendages, i.e., hair, nails, and sebaceous and sweat glands. In contrast, full-thickness wounds are characterized by complete destruction of the epidermis and dermis as well as deeper structures. Repair of tissue loss is initiated by the formation of granulation tissue that replaces the defect before epithelial covering can occur. This form of wound repair is called healing by secondary intention.

Healing by third intention is related to complex cases, e.g., septic conditions when wounds are left intentionally but temporarily open in order to be closed after regression of the highly inflammatory and often life-threatening situation. When the patient is stable and wounds are well-conditioned, wound closure is accomplished by sutures or by plastic surgical reconstruction [21]. This comprehensible classification of wound healing gives an estimate on the duration and course of wound healing phases and, thus, a prediction of later outcomes, e.g., complete skin regeneration or defective tissue repair by scarring.

Superficial, small and clean wounds are usually associated with a short duration of hemostatic and inflammatory phase because blood clot formation is limited to seal the wound with clearing of minor amounts of cell debris. Deep, large and contaminated/infected wounds, however, will need more time to heal as the initial phases of wound healing include longer time for hemostasis and removal of cell debris and necrotic tissue before the start of granulation tissue formation. Reepithelialization already starts some hours after injury by conversion of cobblestone-shaped stationary keratinocytes into flat migratory keratinocytes [22]. In pigs, the epidermis regenerates from hair follicles, apocrine gland ducts, and the 
wound margin, while in humans, this process seems to originate from pilosebaceous units, eccrine sweat glands [22, 23], and the outer root sheath of the hair follicle [24]. Interestingly, the anatomical positioning of skin adnexa seems to be specifically configured for the purpose of highly efficient wound repair. Rittié [22] described this phenomenon by the fact that "no outgrowth has to migrate farther than half the distance that separates two adnexal structures before meeting another outgrowth moving in the opposite direction." With regard to human partial thickness wounds, cells have to cover approximately $500 \mu \mathrm{m}$ of distance and complete epithelialization normally within 8-10 days [23]. The resurfacing of an epidermal wound by migrating keratinocytes was initially described by the term of leapfrogging cells that progressively fall over each other and onto the wound bed without certain migrational activity [25, 26]. Other authors depicted leader cells or even entire cell rows that drag others with them to crawl over the wound [27-30]. Additionally, 3 other mechanisms might also be involved such as extension membrane or epidermal tongue, lamellipodial crawling and shuffling [31, 32]. The epidermal tongue is formed by the front row of keratinocytes adjacent to the wound site. Activated keratinocytes reorganize their cytoskeleton. This is followed by a succeeding advance over the tongue to spread across the wound (leapfrog-like) [22]. The leading row of activated keratinocytes drags them out of blood clot-derived fibrin, fibronectin, and vitronectin (lamellipodial crawling) and forward over the wound matrix. Interestingly, the leading row cells do not migrate centripetally into the wound center but change their shape, loosen their cell-cell contacts, rearrange themselves and leave the front edge (shuffling) [31]. Arrived in the middle of the wound, contact inhibition stops the migratory process of keratinocytes and the wound covering is finished [33]. Firm cell-cell contacts are reestablished and keratinocytes acquire their quiescent cobblestone-shaped phenotype followed by epidermal stratification. Of note, this repair process is performed from top to bottom with the purpose of fast and sufficient wound closure and to prevent further fluid loss or infection. The prerequisite for effective epithelialization is an appropriate ECM that facilitates keratinocyte migration. While adipose tissue, even in thin layers, counteracts wound coverage, tissues such as dermis, fascia or muscle represent optimal wound beds. Except for dermis as underlying substrate, other connective tissues require the formation of granulation tissue for unimpaired epithelial migration. Granulation tissue is constituted of macrophages, fibroblasts, blood vessels and a loose matrix out of type I collagen, glycoprotein, fibronectin, and hyaluronic acid.

After skin injury, the reconstitution of the resulting cellular defect is usually achieved by invading adult stem cells. In the context of epidermal regeneration, stem cells deriving from the hair follicle bulge and the interfollicular epidermis niche replace missing cells [34-36]. A deregulation of the epidermal stem cell niche is present in chronic wounds, i.e., nonhealing ulcers [37], where the cell pool is limited caused by continuous inflammation due to infection, hypoxia, ischemia and/or excessive exudates [38]. The use of stem cells, however, is propagated to overcome the problem of nonhealing wounds with extensive on-going research. Stem cells play an important role in many wound healing phases enabling the resolution of inflammation, cell migration, proliferation and differentiation, although their intriguing role is not yet fully understood [38-40].

\section{Angiogenesis in Skin Wound Healing}

Neovascularization represents an essential component in uncompromised wound healing due to its fundamental impact from the very beginning after skin injury until the end of the wound remodeling $[41,42]$. The (micro)vasculature contributes to the initial hemostasis, reduces blood loss and establishes a provisional wound matrix. Blood clot-derived cytokines and growth factors drive the recruitment of pivotal cells that are crucial for the 
Fig. 1. Schematic cartoon of newly formed microvascular networks of a regenerating skin wound. It depicts the typical arrangement of neovascularization as given by circular vessels (orange) around the wound margins, radial vascular networks (green) building the bridge between the physiological vascular network and the newly formed microvasculature, and the physiological microcirculation running like a net around the hair follicles (blue).

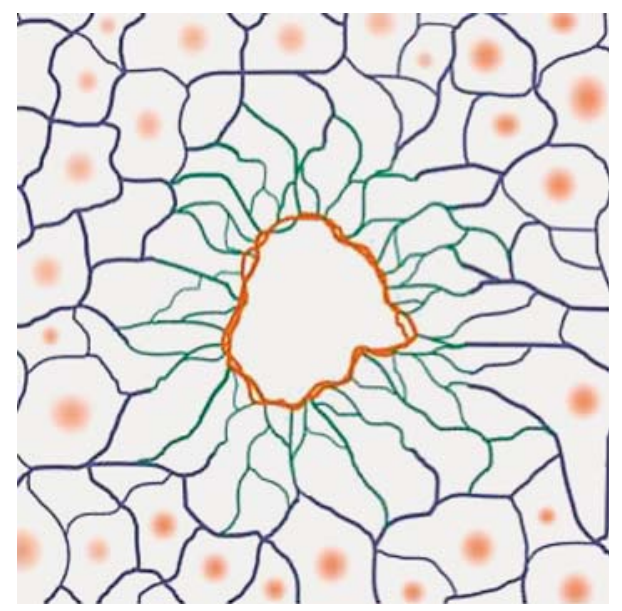

healing process. This provisional wound microenvironment depicts the starting point for new vessel formation and regeneration thereby ensuring the nutritive perfusion of the wound and the delivery of immune cells that remove the cell debris. At first sight, the neovascularization process seems very disordered as the healing wound generates a high density of functional as well as dysfunctional new capillaries. Nonfunctional vessels will regress by time via maturation or apoptotic processes. However, a distinct pattern of the neovascularization process (Fig. 1) can be described forming a circle with an inner ring of circularly organized vessels directly at the wound border followed by radially shaped vessels supplying the inner ones and connecting to the normal, uninjured skin [43]. Disruption in the neovascularization process consecutively leads to wound healing disturbances or chronic ulcers, typically seen in venous insufficiency, arteriosclerotic disease or diabetic foot sores. This pathophysiological phenomenon deserves further attention. Recent research projects focus on blood vessel neoformation and/or delivery to the injury site in order to restore the perfusion and support the healing process. A prerequisite for these approaches is a profound understanding and acknowledgement of the underlying pathophysiological processes that lead to disturbed wound repair.

With regard to chronic, nonhealing wounds, a plethora of causes are present that fuel and feed the unfavorable microenvironment that impedes cutaneous repair. Amongst others, hyperglycemia, persistent inflammation, and growth factor and cytokine deficiencies lead to impaired stem cell recruitment for sufficient angiogenesis [41]. In this context, the beneficial impact of stem cells on skin wound healing is evident, especially for the regeneration of blood vessels [41]. Stem cells or progenitor cells seem to support this process by multiple paracrine effects especially by high levels of pro-angiogenic molecules (i.e., VEGF, HGF, bFGF, EGF, TGF- $\beta$, IGF-1) [44-47]. These effects could be demonstrated in rodent diabetic wounding models, further underscoring the significant activity of stem cells and their potential in repairresistant chronic wounds [45, 46, 48, 49].

Recently, the pericyte received more attention in wound healing issues [50]. First of all, the pericyte is well characterized for its function in vascular development and stabilization of the endothelium in newly formed blood vessels. The pericyte provides blood barriers and regulates capillary flow-through. Furthermore, it acts in a paracrine way and regulates immune responses as well as processes that are associated with scarring or fibrosis. Pericytes provide adhesive substrates, i.e., VCAM-1 and E-selectin but mainly ICAM-1, to initiate neutrophil crawling at the endothelium in search for gates to migrate into the extravascular 
tissue $[5,51-53]$. The anti-inflammatory effect of pericytes manifests in their ability to inhibit antigen-specific activation of chemokine-recruited T cells [54]. Interestingly, pericytes can exert pro-fibrotic activity in that they dedifferentiate into activated fibroblasts producing collagen [55]. Fibroproliferation during hypertrophic scarring might be due to the high sensitivity of pericytes or transdifferentiated myofibroblasts to hypoxic states, resulting in occluded or even partially occluded (micro)vessels [50, 56].

In contrast to previous reports, mounting evidence points to the recognition that the physiological capillary burst after skin injury might be dispensable. Recent research demonstrated that skin wounds healed normally despite reduced angiogenesis [57, 58]. This observation is further supported by the fact that wounds in fetal skin and the oral mucosa heal without scarring despite less angiogenesis compared with adult skin [57, 59]. Less scar formation in fetal skin and oral mucosa might be related to an inferior inflammatory response and a much faster maturation of newly formed capillary networks [57]. New therapies for hypertrophic scars or even keloids have therefore been suggested using anti-angiogenic treatments, although the distinct underlying mechanism is still unclear [57, 60, 61]. DiPietro [57] concluded in her review article that at first, it might seem odd to diminish angiogenesis during skin wound repair. However, as long as nutritive perfusion is provided, a reduced number of capillaries might be sufficient to promote normal skin regeneration.

\section{Remodeling in Skin Wound Healing and Scarring}

Scar formation demarcates the end of the last wound healing phase, e.g., the remodeling phase. In contrast to fetal wound repair, normal adult wound healing ultimately results in wound closure and replacement of the original tissue with a collagenous scar. The miracle of perfect, scarless embryonic wound repair is currently poorly understood.

The early-gestation fetus can heal skin wounds with regenerative-type repair and without scar formation $[62,63]$. In scarless fetal wounds, the epidermis and dermis are restored to a normal architecture. The collagen dermal matrix pattern is reticular and unchanged from unwounded dermis. The wound hair follicle and sweat gland patterns are normal as well. Previous studies on fetal wound repair in sheep showed that wounds healed with complete skin restoration until the end of the second trimenon. In humans, however, scarring occurs earlier in fetal wound repair [64]. This might be due to the specific response of fetal fibroblasts to the pro-fibrotic mediator TGF- $\beta$ [65].

Scar formation is the ultimate outcome of wound repair in children and adults. Cutaneous scars have no epidermal appendages (hair follicles and sebaceous glands) and a collagen pattern that is distinctly different from unwounded skin. New collagen fibers secreted by fibroblasts are present as early as 3 days after wounding. As the collagen matrix forms, densely packed fibers fill the wound site. The ultimate pattern of collagen in scar is one of densely packed fibers and not the reticular pattern found in unwounded dermis.

To understand the physiology of normal scarring and the pathophysiology of hypertrophic scarring (Fig. 2), one has to be familiar with the role of fibroblasts and myofibroblasts in skin wound healing. It has become accepted that myofibroblasts play a key role in wound contraction. After wounding, dermal fibroblasts at wound margins are activated by growth factors released into the wound. Stimulated by mechanical tension and platelet-derived growth factor (PDGF), they turn into stress fiber-expressing protomyofibroblasts. Protomyofibroblasts are found in early granulation tissue and in normal connective tissue with high mechanical load. Approximately 4 days after wounding, myofibroblasts appear in the wound [66]. Mechanical tension, activated TGF- $\beta$ [67] and the splice variant EDA fibronectin trigger protofibroblast differentiation into $\alpha$-smooth muscle actin-expressing myofibroblasts [68]. 

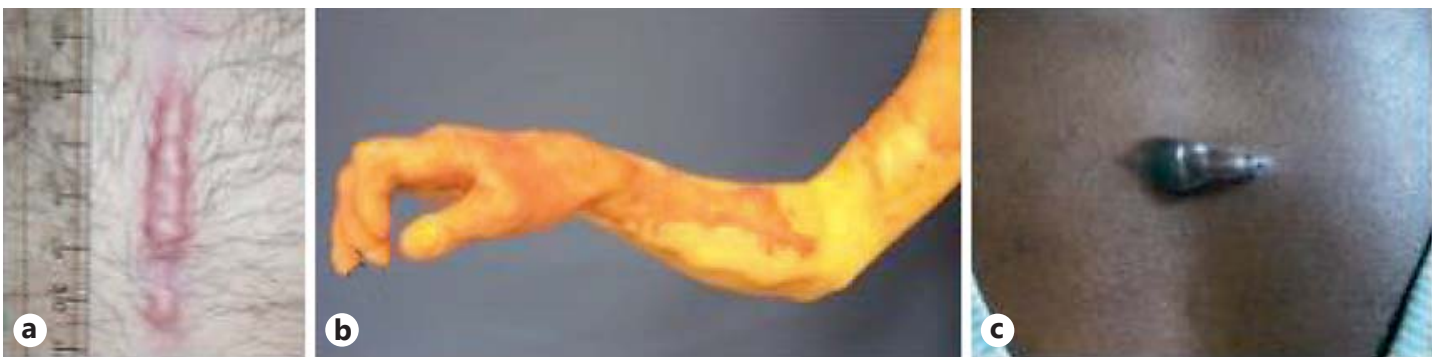

Fig. 2. Examples for different scar types. a Linear hypertrophic scar after midline sternotomy. b Wide-spread hypertrophic scars after burn injury with scar contractures impairing movement of fingers and the hand. c Keloid scar after presternal folliculitis.

Myofibroblasts exert their contractile forces by focal adhesion contacts that link the intracellular cytoskeleton to the ECM. Wound contraction must be distinguished from contracture. Clinically, contracture is defined as tissue shortening or distortion that causes decreased joint mobility and function. Scar contracture commonly refers to decreased function in the area, whereas scar contraction refers to shortening of the scar length compared with the original wound (Fig. 2b). Wound scar remodeling occurs during months to years to form a mature scar. The early scar appearance is red due to its dense capillary network induced at the injury site. When closure is complete, capillaries regress until relatively few remain. As the scar redness dissipates during a period of months, the true scar pigmentation becomes evident. Scars are usually hypopigmented after full maturation. However, scars can become hyperpigmented in darker-pigmented patients and in those lighter-pigmented patients whose scars receive excessive sun exposure. For this reason, sun protection measures are recommended for patients with early scars on sun-exposed areas such as the scalp, face, and neck. During remodeling, wounds gradually become stronger with time.

Growth factors are the focal regulatory points of the repair process. They are polypeptides that are released by a variety of activated cells at the wound site. In general, they stimulate cellular proliferation and chemoattract new cells to the wound. Myriad growth factors are present in wounds and many have overlapping biologic functions. PDGF is released from platelet $\alpha$-granules immediately after injury. It attracts neutrophils, macrophages, and fibroblasts to the wound and serves as a powerful mitogen. Moreover, it stimulates fibroblasts to synthesize new ECM and strongly induces granulation tissue production. TGF- $\beta_{1}$ predominates in adult wound healing and is a pro-migratory and pro-fibrotic growth factor that directly stimulates collagen synthesis and decreases ECM degradation by fibroblasts. It is released from all cells at the wound site, including platelets, macrophages, fibroblasts, and keratinocytes. TGF- $\beta$ accelerates wound repair when it is applied experimentally to wounds that have no deficiency in repair. However, the increase in the repair rate is at the expense of increased fibrosis, which could be a detriment during normal skin healing.

Normal wounds have "stop" signals that halt the repair process when the dermal defect is closed and epithelialization is complete. When these signals are absent or ineffective, the repair process may continue unabated and cause excessive scar. The underlying molecular mechanisms leading to excessive repair are still a topic of intensive research. Pro-fibrotic cytokine overexpression and reduction of collagenase activity were found in skin tissue of burn patients [69]. A lack of programmed cell death, i.e., apoptosis, at the conclusion of repair with the continued presence of activated fibroblasts secreting ECM components has also been implicated [70]. 
Notwithstanding the molecular regulation of excessive scar formation, there are clinical factors that affect it. To minimize a visible cutaneous scar, elective incisions are least noticeable when they are placed parallel to the natural lines of skin tension (Langer's lines). This placement has 2 advantages: the scar is parallel or within a natural skin crease, which camouflages the scar, and this location places the least amount of tension on the wound. Wound tension widens the scar. Sharply defined and well-aligned wound edges that are approximated without tension heal with the least amount of scar. Infection or separation of the wound edges with subsequent secondary intention healing also results in more scar formation. Hyperpigmentation and hypopigmentation of the scar increase its contrast with the surrounding skin, making the scar more visible. Sun protection of all wounds is recommended to prevent scar hyperpigmentation.

Hypertrophic scars and keloids (Fig. 2a-c) are unique to humans and very rarely occur in animals, e.g., on horses' legs or after severe burns [71]. Pathologic scar types are distinguished on the basis of their clinical characteristics. Hypertrophic scars are defined as scars that have not overgrown the original wound boundaries but are instead raised, reddish and itchy (Fig. 2a). They usually form secondary to excessive tensile forces across the wound and are most common in wounds across joint surfaces on the extremities but also commonly occur on the sternum and neck. Physical therapy with range-of-motion exercises is helpful in minimizing hypertrophic scar as well as joint contracture in the extremities. Hypertrophic scar is a self-limited type of overhealing that can regress with time. These scars generally fade as well as flatten to the surrounding skin level.

The first step toward treatment of excessive scarring is early recognition and institution of therapy after surgery or trauma. Meticulous tissue handling, suturing, and wound management with efforts to prevent infection are mandatory [72]. Sun protection to reduce scar hyperpigmentation is essential. Patients who are at increased risk of excessive scarring benefit from preventive techniques, which include silicone gel sheeting or ointments, hypoallergenic microporous tape, and concurrent intralesional steroid injection [72, 73]. Silicone gel sheeting is widely used for hypertrophic scar treatment and the only remedy with high evidence [74]. Silicone gel sheeting has a 20-plus-year history with several randomized controlled trials that support its safe and effective use $[73,75]$. Proposed mechanisms of action for scar reduction include improved hydration and occlusion, increased temperature and change in scar mechanical tension.

A great deal of research is focused on the development of treatment strategies to reduce or prevent scarring. Prompted by fetal wound-healing observations, investigators initially analyzed the anti-scarring effect of anti-TGF- $\beta$ strategies. The complexity of scar formation and remodeling is underpinned by the fact that simple addition of anti-fibrotic TGF- $\beta_{3}$ was insufficient to prevent scarring [76]. Clearly, more studies are needed, and because of the redundancy of action among growth factors, TGF- $\beta$ is likely not to be the only growth factor targeted to reduce human scar formation and fibrosis. Lately, tissue mechanics, duration of wound closure and intensity of the inflammatory reaction have come more into focus to address excessive scarring.

Clinical phase II and III trials are currently performed using several novel drugs to tackle fibrotic diseases [77]. Amongst others, the effect of antibodies against TGF- $\beta$, the integrin $\alpha v \beta 6$, interleukin- 13 , connective tissue growth factor CTGF/CCN2 and many more is investigated in lung or liver fibrosis or in keloids. Surprisingly, systemic treatment with leukotriene receptor antagonists, angiotensin-converting enzyme, calcium antagonists or statins for asthma, hypertension or hypercholesterinemia, respectively, coincided with reduced scarring [78]. These incidental effects could be, in part, reproduced in animal models [79]. Hopefully, on-going clinical studies will yield sufficient and convincing results for future treatment of excessive scarring. 


\section{Tissue Engineering and Cell-Based Therapy for Wound Healing}

Currently, the surgical state of the art for the covering of wounds displays autologous skin grafting, which is, however, limited by the availability of autologous skin. Even though the plastic surgical armamentarium comprises a diverse spectrum for tissue transfer, the efforts do not resemble true tissue regeneration or replacements yet. Tissue engineering seeks to create replacement tissues to restore or maintain organ function and to repair tissue defects [40]. Recreating an environment that promotes fundamental homeostatic mechanisms is a significant challenge in tissue engineering [80]. Optimizing cell survival, proliferation, differentiation, apoptosis and angiogenesis and provide suitable stromal support and signaling clues are the key to successfully generating clinically useful tissue [81]. The increasing knowledge of molecular and cellular mechanisms and lessons learned through frustrated attempts enables us to better define future directions, taking into account the various underlying pathophysiological conditions and differing wound types and their specific requirements. Independent of the tissue engineering product, a meticulous wound bed preparation, minimizing bacterial burden, thorough debridement of nonviable tissue, control of edema, optimizing the vascular status to allow for optimal nutrient supply, prevent additional trauma and reduction of mechanical stress are fundamental prerequisites for successful wound healing. Various tissue engineering approaches ranging from temporary wound dressings to improve wound milieu to acellular scaffolds to cell transplants and dermal substitutes are being investigated focusing on many different growth factors, as already mentioned above. Yet the orchestra of growth factors is numerous and the timely interaction is not completely explored, hence further research is needed to provide the appropriate cell signaling clues to promote true wound regeneration.

Another widely studied aspect is the field of matrix materials and scaffolds to provide structural support and promote cell migration. A variety of different components for skin substitutes are being examined each with their unique physical (pore size, elasticity) and biological (cell adhesion, cell migration) characteristics, such as collagens, fibrin/fibronectin, chitosan, elastin, gelatin and glycosaminoglycans [82-86]. Furthermore, decellularization of allogenic or xenogenic skin, 3D printing and currently genetic modifications of the wound bed offer new perspectives $[40,87]$. In addition, cell transplantation either incorporated in the matrix material or implanted in the wound bed has gained recent interest. Stem and progenitor cells originally thought to replace organ-specific cells have recently been discovered to also deploy their potential for wound healing through chemotaxis of host cells and as a source for cell signaling molecules. However, none of the above-mentioned research work has found its way to standardized clinical application yet [40]. In summary, an optimal dermal substitute or skin replacement therapy has not been found yet by means of tissue engineering. With increasing knowledge about cellular interaction and cell signaling as well as the pathophysiological requirements of specific wound conditions, tissue engineering holds great perspectives for the future to enhance wound healing.

\section{Plasma}

Plasma is a well-known phenomenon in daily life. Almost 99\% of all materials, based on the whole universe, consist of plasma. In physics, plasma is a particle mixture at the atomicmolecular level, the components of which are partially charged components, ions, and electrons. This means that plasma contains free charge carriers. In addition to the 3 classical aggregate states (solid, liquid, gaseous), plasma is considered a further state of matter. A characteristic of plasma, which is essential for its behavior, but also for technical use, is, therefore, 
Fig. 3. a Argon plasma application to blood agar plates. $\mathbf{b}$ Treatment of burn wounds by 3 argon plasma applicators.

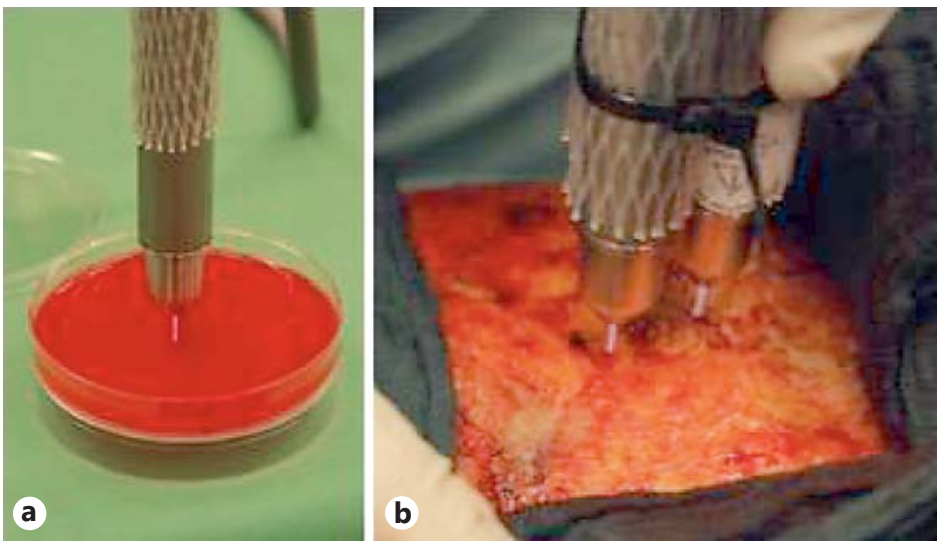

its electrical conductivity. On earth, there are natural plasmas in the ionosphere and lightning. In the biosphere, there are no practically usable natural plasmas. Therefore, plasma must be generated in order to be able to apply it technically. This is usually done by gas discharge. Neon tubes, plasma TVs and nuclear fusion are examples of regular application of plasma technique. In medical engineering, plasma already has a wide spectrum of use, e.g., in surface treatments and meanwhile plasma application is used in cauterization and operative debridement. After years of technological progress, plasma is now ready for medical application. That means, electric currents and temperature are now tolerable for medical application in vivo (Fig. 3). The functional principle is the electric stimulation of argon gas that produces a plasma flame with tolerable temperatures and currencies (Fig. 3). Different studies gave evidence of the successful decontamination of multidrug-resistant, contaminated wounds through nonthermal plasma (NTP) or cold atmospheric plasma (CAP) [88-90]. A secondary beneficial feature of plasma derives from its genomic effects [91]. To examine wound healing activity of an atmospheric pressure plasma jet in vivo aside from decontamination effects, Schmidt et al. [92] examined the efficacy of CAP on dermal regeneration in a model of dermal full-thickness ear wounds in mice. Herein, the study could show significantly accelerated wound reepithelialization from day 3 to 9 compared to untreated controls. This was further underscored by in vitro studies, showing enhanced migratory behavior of keratinocytes and fibroblasts. Gap closure in wound scratch assays was significantly accelerated in CAP-treated cells [92]. Keratinocytes mainly regenerate the epidermis and play an important role in wound closure. Daily short plasma applications (up to 40 s) to murine superficial skin wounds showed significantly increased epidermal cell regeneration, granulation tissue hyperplasia, and collagen deposition [93]. This was also confirmed by plasma application on human skin biopsies where short CAP exposure (1-3 min) was already able to induce the proliferation of keratinocytes [94]. Concomitantly, longer exposures might lead to overdosing of the plasma application inducing apoptotic cell death with a further disturbed wound healing process $[93,94]$. Chernets et al. [95] examined appendage regeneration stimulated by NTP dependent on reactive oxidative species. Single treatment of in vitro organ culture systems with NTP was already able to enhance the survival, growth, and elongation of mouse limb autopods. Perceptible transformations comprised an improved development of the digit length as well as the definition of digit separation [95]. In our own group, we have treated cultivated fibrocytes with NTP for different periods [unpublished data]. Like the effects of plasma on keratinocytes, only short-term treatments with NTP showed expression of macrophage migration inhibitory factor. This cytokine plays an important role in wound healing processes by significantly influencing the expression of anti-microbial peptides from the $\beta$-defensin family, important actors for the cellular pathogen defense. 


\section{Conclusion}

The integrity of healthy skin plays an important role in maintaining physiological homeostasis of the human body. Many instances are described which lead to insufficient healing necessitating further intervention. Although wound healing mechanisms and specific cell functions in wound repair have been delineated in part, many underlying pathophysiological processes are still unknown and we are only able to design new and effective wound healing therapies if we better understand this complex interplay. The here presented new perspectives further support the enormous importance of research in this field in order to reduce the incidence of nonhealing wounds and to facilitate the healing process in general.

\section{Disclosure Statement}

The authors declare no conflicts of interest.

\section{References}

1 Landén NX, Li D, Ståhle M: Transition from inflammation to proliferation: a critical step during wound healing. Cell Mol Life Sci 2016;73:3861-3885.

2 Strbo N, Yin N, Stojadinovic O: Innate and adaptive immune responses in wound epithelialization. Adv Wound Care 2014;3:492-501.

3 Takeuchi 0, Akira S: Pattern recognition receptors and inflammation. Cell 2010;140:805-820.

4 Sinno H, Prakash S: Complements and the wound healing cascade: an updated review. Plast Surg Int 2013; 2013:1-7.

5 Vestweber D: How leukocytes cross the vascular endothelium. Nat Rev Immunol 2015;15:692-704.

6 Eming SA, Martin P, Tomic-Canic M: Wound repair and regeneration: mechanisms, signaling, and translation. Sci Transl Med 2014;6:265sr6-265sr6.

7 Eming SA, Brachvogel B, Odorisio T, Koch M: Regulation of angiogenesis: wound healing as a model. Prog Histochem Cytochem 2007;42:115-170.

8 Werner S, Grose R: Regulation of wound healing by growth factors and cytokines. Physiol Rev 2003;83:835870.

9 Nosbaum A, Prevel N, Truong HA, Mehta P, Ettinger M, Scharschmidt TC, et al: Cutting edge: regulatory T cells facilitate cutaneous wound healing. J Immunol 2016;196:2010-2014.

10 Sindrilaru A, Scharffetter-Kochanek K: Disclosure of the culprits: macrophages-versatile regulators of wound healing. Adv Wound Care 2013;2:357-368.

11 Lucas T, Waisman A, Ranjan R, Roes J, Krieg T, Muller W, et al: Differential roles of macrophages in diverse phases of skin repair. J Immunol 2010;184:3964-3977.

12 Galli SJ, Borregaard N, Wynn TA: Phenotypic and functional plasticity of cells of innate immunity: macrophages, mast cells and neutrophils. Nat Immunol 2011;12:1035-1044.

13 Mosser DM, Edwards JP: Exploring the full spectrum of macrophage activation. Nat Rev Immunol 2008;8: 958-969.

14 Brancato SK, Albina JE: Wound macrophages as key regulators of repair. Am J Pathol 2011;178:19-25.

15 Fadok VA, Bratton DL, Konowal A, Freed PW, Westcott JY, Henson PM: Macrophages that have ingested apoptotic cells in vitro inhibit proinflammatory cytokine production through autocrine/paracrine mechanisms involving TGF-beta, PGE2, and PAF. J Clin Invest 1998;101:890-898.

16 Sindrilaru A, Peters T, Wieschalka S, Baican C, Baican A, Peter H, et al: An unrestrained proinflammatory M1 macrophage population induced by iron impairs wound healing in humans and mice. J Clin Invest 2011;121: 985-997.

17 Mirza RE, Fang MM, Novak ML, Urao N, Sui A, Ennis WJ, et al: Macrophage PPAR $\gamma$ and impaired wound healing in type 2 diabetes. J Pathol 2015;236:433-444.

18 Khanna S, Biswas S, Shang Y, Collard E, Azad A, Kauh C, et al: Macrophage dysfunction impairs resolution of inflammation in the wounds of diabetic mice. PLoS One 2010;5:e9539.

19 Martin P, D’Souza D, Martin J, Grose R, Cooper L, Maki R, et al: Wound healing in the PU.1 null mouse - tissue repair is not dependent on inflammatory cells. Curr Biol 2003;13:1122-1128.

20 Volk SW, Bohling MW: Comparative wound healing: are the small animal veterinarian's clinical patients an improved translational model for human wound healing research? Wound Repair Regen 2013;21:372-381.

21 Knobloch K, Vogt PM: Die rekonstruktive Sequenz des 21. Jahrhunderts. Chirurg 2010;81:441-446. 
22 Rittié L: Cellular mechanisms of skin repair in humans and other mammals. J Cell Commun Signal 2016:10 103-120.

23 Rittié L, Sachs DL, Orringer JS, Voorhees JJ, Fisher GJ: Eccrine sweat glands are major contributors to reepithelialization of human wounds. Am J Pathol 2013;182:163-171.

24 Rittié L, Farr EA, Orringer JS, Voorhees JJ, Fisher GJ: Reduced cell cohesiveness of outgrowths from eccrine sweat glands delays wound closure in elderly skin. Aging Cell 2016;15:842-852.

25 Krawczyk WS: A pattern of epidermal cell migration during wound healing. J Cell Biol 1971;49:247-263.

26 Lambert WC, Cohen PJ, Lambert MW: Role of the epidermis and other epithelia in wound healing: selected concepts. Clin Dermatol 1984;2:24-33.

27 Gov NS: Collective cell migration patterns: follow the leader. Proc Natl Acad Sci USA 2007;104:15970-15971.

28 Omelchenko T, Vasiliev JM, Gelfand IM, Feder HH, Bonder EM: Rho-dependent formation of epithelial "leader" cells during wound healing. Proc Natl Acad Sci USA 2003;100:10788-10793.

29 Farooqui R, Fenteany G: Multiple rows of cells behind an epithelial wound edge extend cryptic lamellipodia to collectively drive cell-sheet movement. J Cell Sci 2004;118:51-63.

30 Matsubayashi Y, Razzell W, Martin P: "White wave" analysis of epithelial scratch wound healing reveals how cells mobilise back from the leading edge in a myosin-II-dependent fashion. J Cell Sci 2011;124:1017-1021.

31 Jacinto A, Martinez-Arias A, Martin P: Mechanisms of epithelial fusion and repair. Nat Cell Biol 2001;3:E117E123.

32 Stone RC, Pastar I, Ojeh N, Chen V, Liu S, Garzon KI, et al: Epithelial-mesenchymal transition in tissue repair and fibrosis. Cell Tissue Res 2016;365:495-506.

33 Santoro MM, Gaudino G: Cellular and molecular facets of keratinocyte reepithelization during wound healing. Exp Cell Res 2005;304:274-286.

34 Blanpain C, Fuchs E: Plasticity of epithelial stem cells in tissue regeneration. Science 2014;344:12422811242281.

35 Donati G, Watt FM: Stem cell heterogeneity and plasticity in epithelia. Cell Stem Cell 2015;16:465-476.

36 Pastar I, Stojadinovic O, Yin NC, Ramirez H, Nusbaum AG, Sawaya A, et al: Epithelialization in wound healing: a comprehensive review. Adv Wound Care 2014;3:445-464.

37 Stojadinovic 0, Pastar I, Nusbaum AG, Vukelic S, Krzyzanowska A, Tomic-Canic M: Deregulation of epidermal stem cell niche contributes to pathogenesis of nonhealing venous ulcers. Wound Rep Regen 2014;22:220-227.

38 Chen D, Hao H, Fu X, Han W: Insight into reepithelialization: how do mesenchymal stem cells perform? Stem Cells Int 2016;2016:6120173.

39 Yang M, Li Q, Sheng L, Li H, Weng R, Zan T: Bone marrow-derived mesenchymal stem cells transplantation accelerates tissue expansion by promoting skin regeneration during expansion. Ann Surg 2011;253:202-209.

40 Tenenhaus M, Rennekampff H-O: Current concepts in tissue engineering. Plast Reconstr Surg 2016;138:42S$50 \mathrm{~S}$.

41 Demidova-Rice TN, Durham JT, Herman IM: Wound healing angiogenesis: innovations and challenges in acute and chronic wound healing. Adv Wound Care 2012;1:17-22.

42 Dulmovits BM, Herman IM: Microvascular remodeling and wound healing: a role for pericytes. Int J Biochem Cell Biol 2012;44:1800-1812.

43 Sorg H, Krueger C, Vollmar B: Intravital insights in skin wound healing using the mouse dorsal skin fold chamber. J Anat 2007;211:810-818.

44 Kusindarta DL, Wihadmadyatami H, Fibrianto YH, Nugroho WS, Susetya H, Musana DK, et al: Human umbilical mesenchymal stem cells conditioned medium promote primary wound healing regeneration. Vet World 2016; 9:605-610.

45 Milan PB, Lotfibakhshaiesh N, Joghataie MT, Ai J, Pazouki A, Kaplan DL, et al: Accelerated wound healing in a diabetic rat model using decellularized dermal matrix and human umbilical cord perivascular cells. Acta Biomaterialia 2016; 45:234-246.

46 Kong P, Xie X, Li F, Liu Y, Lu Y: Placenta mesenchymal stem cell accelerates wound healing by enhancing angiogenesis in diabetic Goto-Kakizaki (GK) rats. Biochem Biophys Res Commun 2013;438:410-419.

47 Bodnar RJ: Chemokine regulation of angiogenesis during wound healing. Adv Wound Care 2015;4:641-650.

48 Barcelos LS, Duplaa C, Krankel N, Graiani G, Invernici G, Katare R, et al: Human CD133+ progenitor cells promote the healing of diabetic ischemic ulcers by paracrine stimulation of angiogenesis and activation of Wnt signaling. Circulation Res 2009;104:1095-1102.

49 Lee K-B, Choi J, Cho S-B, Chung J-Y, Moon E-S, Kim N-S, et al: Topical embryonic stem cells enhance wound healing in diabetic rats. J Orthop Res 2011;29:1554-1562.

50 Bodnar RJ, Satish L, Yates CC, Wells A: Pericytes: a newly recognized player in wound healing. Wound Rep Regen 2016;24:204-214.

51 Proebstl D, Voisin M-B, Woodfin A, Whiteford J, D’Acquisto F, Jones GE, et al: Pericytes support neutrophil subendothelial cell crawling and breaching of venular walls in vivo. J Exp Med 2012;209:1219-1234.

52 Voisin M-B, Nourshargh S: Neutrophil transmigration: emergence of an adhesive cascade within venular walls. J Innate Immun 2013;5:336-347.

53 Ayres-Sander CE, Lauridsen H, Maier CL, Sava P, Pober JS, Gonzalez AL: Transendothelial migration enables subsequent transmigration of neutrophils through underlying pericytes. PLoS One 2013;8:e60025.

54 Pober JS, Tellides G: Participation of blood vessel cells in human adaptive immune responses. Trends Immunol 2012;33:49-57. 
55 Humphreys BD, Lin S-L, Kobayashi A, Hudson TE, Nowlin BT, Bonventre JV, et al: Fate tracing reveals the pericyte and not epithelial origin of myofibroblasts in kidney fibrosis. Am J Pathol 2010;176:85-97.

56 Yemisci M, Gursoy-Ozdemir Y, Vural A, Can A, Topalkara K, Dalkara T: Pericyte contraction induced by oxidative-nitrative stress impairs capillary reflow despite successful opening of an occluded cerebral artery. Nat Med 2009;9:1031-1038.

57 DiPietro LA: Angiogenesis and wound repair: when enough is enough. J Leukoc Biol 2016;100:979-984.

58 Wietecha MS, Król MJ, Michalczyk ER, Chen L, Gettins PG, DiPietro LA: Pigment epithelium-derived factor (PEDF) as a multifunctional regulator of wound healing. Am J Physiol Heart Circ Physiol 2015;309:H812H826.

59 Szpaderska AM, Walsh CG, Steinberg MJ, DiPietro LA: Distinct patterns of angiogenesis in oral and skin wounds. J Dent Res 2005;84:309-314.

60 Mogili NS, Krishnaswamy VR, Jayaraman M, Rajaram R, Venkatraman A, Korrapati PS: Altered angiogenic balance in keloids: a key to therapeutic intervention. Transl Res 2012;159:182-189.

61 Diao J-S, Xia W-S, Guo S-Z: Bevacizumab: a potential agent for prevention and treatment of hypertrophic scar. Burns 2010;36:1136-1137.

62 Buchanan EP, Longaker MT, Lorenz HP: Fetal skin wound healing. Adv Clin Chem 2009;48:137-161.

63 Lorenz HP, Whitby DJ, Longaker MT, et al: Fetal wound healing. The ontogeny of scar formation in the nonhuman primate. Ann Surg 1993;217:391-396.

64 Walraven M: Cellular and molecular mechanisms involved in scarless wound healing in the fetal skin; PhD thesis, Amsterdam, 2016.

65 Walraven M, Gouverneur M, Middelkoop E, Beelen RHJ, Ulrich MMW: Altered TGF- $\beta$ signaling in fetal fibroblasts: what is known about the underlying mechanisms? Wound Repair Regen 2014;22:3-13.

66 Tomasek JJ, Gabbiani G, Hinz B, Chaponnier C, Brown RA: Myofibroblasts and mechano-regulation of connective tissue remodelling. Nat Rev Mol Cell Biol 2002;3:349-363.

67 Mirastschijski U, Schnabel R, Claes J, Schneider W, Agren MS, Haaksma C, et al: Matrix metalloproteinase inhibition delays wound healing and blocks the latent transforming growth factor- $\beta 1$-promoted myofibroblast formation and function. Wound Rep Regen 2010;18:223-234.

68 Hinz B, Mastrangelo D, Iselin CE, Chaponnier C, Gabbiani G: Mechanical tension controls granulation tissue contractile activity and myofibroblast differentiation. Am J Pathol 2001;159:1009-1020.

69 Armour A, Scott PG, Tredget EE: Cellular and molecular pathology of HTS: basis for treatment. Wound Repair Regen 2007;15(suppl 1):S6-S17.

70 Wassermann RJ, Polo M, Smith P, Wang X, Ko F, Robson MC: Differential production of apoptosis-modulating proteins in patients with hypertrophic burn scar. J Surg Res 1998;75:74-80.

71 Ud-Din S, Volk SW, Bayat A: Regenerative healing, scar-free healing and scar formation across the species: current concepts and future perspectives. Exp Dermatol 2014;23:615-619.

72 Mustoe TA, Cooter RD, Gold MH, Hobbs FDR, Ramelet A-A, Shakespeare PG, et al: International clinical recommendations on scar management. Plast Reconstr Surg 2002;110:560-571.

73 Monstrey S, Middelkoop E, Vranckx JJ, Bassetto F, Ziegler UE, Meaume S, et al: Updated scar management practical guidelines: non-invasive and invasive measures. J Plast Reconstr Aesthet Surg 2014;67:1017-1025.

74 O'Brien L, Jones DJ: Silicone gel sheeting for preventing and treating hypertrophic and keloid scars. Cochrane Database Syst Rev 2013;9:CD003826.

75 Van den Kerckhove E, Stappaerts K, Fieuws S, Laperre J, Massagé P, Flour M, et al: The assessment of erythema and thickness on burn related scars during pressure garment therapy as a preventive measure for hypertrophic scarring. Burns 2005;31:696-702.

76 Occleston NL, O'Kane S, Goldspink N, Ferguson MWJ: New therapeutics for the prevention and reduction of scarring. Drug Discov Today 2008;13:973-981.

77 Hinz B: Targeting myofibroblast to improve wound healing; in Ågren M (ed): Wound Healing Biomaterials. Cambridge, Woodhead Publishing, 2016, vol 1.

78 Iannello S, Milazzo P, Bordonaro F: Low-dose enalapril in the treatment of surgical cutaneous hypertrophic scar and keloid: two case reports and literature review. MedGenMed 2006;8:60-67.

79 Ko JH, Kim PS, Zhao Y, Hong SJ, Mustoe TA: HMG-CoA reductase inhibitors (statins) reduce hypertrophic scar formation in a rabbit ear wounding model. Plast Reconstr Surg 2012;129:252e-261e.

80 Nicholas MN, Jeschke MG, Amini-Nik S: Methodologies in creating skin substitutes. Cell Mol Life Sci 2016;73: 3453-3472.

81 Tilkorn DJ, Lokmic Z, Chaffer CL, Mitchell GM, Morrison WA, Thompson EW: Disparate companions: tissue engineering meets cancer research. Cells Tissues Organs 2010;192:141-157.

82 Ojeh N, Pastar I, Tomic-Canic M, Stojadinovic 0: Stem cells in skin regeneration, wound healing, and their clinical applications. Int J Mol Sci 2015;16:25476-25501.

83 Corin KA, Gibson LJ: Biomaterials. Biomaterials 2010;31:4835-4845.

84 Dickinson LE, Gerecht S: Engineered biopolymeric scaffolds for chronic wound healing. Front Physiol 2016;7: 623.

85 Salamone JC, Salamone AB, Swindle-Reilly K, Leung KX-C, McMahon RE: Grand challenge in Biomaterialswound healing. Regen Biomater 2016;3:127-128.

86 Zhong SP, Zhang YZ, Lim CT: Tissue scaffolds for skin wound healing and dermal reconstruction. Wiley Interdiscip Rev Nanomed Nanobiotechnol 2010;2:510-525. 
87 Priya SG, Jungvid H, Kumar A: Skin tissue engineering for tissue repair and regeneration. Tissue Eng Part B Rev 2008;14:105-118.

88 Daeschlein G, Napp M, Lutze S, Arnold A, Podewils von S, Guembel D, et al: Skin and wound decontamination of multidrug-resistant bacteria by cold atmospheric plasma coagulation. J Ger Soc Dermatol 2015;13:143150.

89 Ermolaeva SA, Sysolyatina EV, Gintsburg AL: Atmospheric pressure nonthermal plasmas for bacterial biofilm prevention and eradication. Biointerphases 2015;10:029404.

90 Matthes R, Bender C, Schlüter R, Koban I, Bussiahn R, Reuter S, et al: Antimicrobial efficacy of two surface barrier discharges with air plasma against in vitro biofilms. PLoS One 2013;8:e70462.

91 Ma Y, Ha CS, Hwang SW, Lee HJ, Kim GC, Lee K-W, et al: Non-thermal atmospheric pressure plasma preferentially induces apoptosis in p53-mutated cancer cells by activating ROS stress-response pathways. PLoS One 2014;9:e91947.

92 Schmidt A, Bekeschus S, Wende K, Vollmar B, Woedtke von T: A cold plasma jet accelerates wound healing in a murine model of full-thickness skin wounds. Exp Dermatol 2016, Epub ahead of print.

93 Xu G-M, Shi X-M, Cai J-F, Chen S-L, Li P, Yao C-W, et al: Dual effects of atmospheric pressure plasma jet on skin wound healing of mice. Wound Repair Regen 2015;23:878-884.

94 Hasse S, Duong Tran T, Hahn O, Kindler S, Metelmann HR, Woedtke von T, et al: Induction of proliferation of basal epidermal keratinocytes by cold atmospheric-pressure plasma. Clin Exp Dermatol 2015;41:202-209.

95 Chernets N, Zhang J, Steinbeck MJ, Kurpad DS, Koyama E, Friedman G, et al: Nonthermal atmospheric pressure plasma enhances mouse limb bud survival, growth, and elongation. Tissue Eng Part A 2015;21:300-309. 